\title{
Experimental study on the compression properties of degraded municipal solid waste
}

\author{
Z. Zhang, D. Wu, L. Yan, Z. Ding, Y. Wang \& S. Lei \\ School of Civil Engineering and Architecture, \\ Zhejiang Sci-Tech University, China
}

\begin{abstract}
The compression characteristics of degraded municipal solid waste were studied by using large scale compression apparatus. The municipal solid waste materials were divided into three parts which were: easily degradable, difficult to degrade, and incompressible solid waste material in a geo-environmental laboratory. Three mixture proportions, three different initial densities, four different degraded times, four different pressures, and eight different compression times were selected for the compression test. The test results show that: (1) The total strain of degraded municipal solid waste increases with vertical pressure, and the relationship can be described as a logarithmic model; (2) The total strain of degraded municipal solid waste increases with initial density, and the relationship can be formulated as a linear relation; (3) The density of degraded municipal solid waste increases with degradation time, and the relationship can be expressed as a logarithmic model.

Keywords: experimental study, compression property, degraded municipal solid waste, logarithmic model, linear relation.
\end{abstract}

\section{Introduction}

With the steady increase of municipal solid waste (MSW) year by year, a lot of landfills will be constructed at present and in the future. During the construction process and the operation process, accident such as collapse and slip of a landfill happens occasionally. The landfill of Kettleman Hills, located in America, was destroyed by the lateral sliding failure in March 1988. Another accident was the slump of the Manila landfill, located in Philippines. It happened after a heavy rain on July 10th, 2000, and caused 100 people lost their lives and more than 100 people were injured. The reasons which caused the collapse of a landfill have 
much connection with the large deformation of the landfill. Therefore, it is necessary to investigate the compression characteristics of degraded MSW. Sower $[1,2]$ studied the foundation problem of a landfill, pointed out that the settlement of a landfill consisted of main settlement and secondary settlement, and gave the range of the primary compression indexed and the secondary compression indexed which based on the measured data. Yue and Scanlon [3] analyzed the settlement velocity of a landfill, and proposed a settlement model for the landfill. Gabr and Valero [4] utilized a ring with the diameter and height were $63 \mathrm{~mm}$ and $22 \mathrm{~mm}$ respectively, and carried out the compression test, and gained the compression characteristics of MSW. Hanson et al. [5] overviewed the compression properties of MSW, and analyzed the influence of water content on the compression properties of MSW by indoor test and field test. Hu et al. [6] studied the variation of organic matter content and degradation regulation during the degradation process, and analyzed the influence of the distribution and change of void ratio on the compression of MSW. Ke et al. [7] studied change regulation of the organic matter content with the depth, and established a simplified calculation formula for the settlement of MSW, and used this formula to analyze the influence of organic matter content and degradation velocity on the biodegradation compression of MSW. Zhang and Chen [8] and Zhang [9] investigated the settlement and deformation mechanism of a landfill, pointed out a settlement calculation model which consisted of the compression settlement under the vertical pressure and the settlement caused by the organic matter degradation, and gave the change regulation of the settlement with time. Chen et al. [10] selected the Shenzhen Xiaping landfill as an example, carried out the degradation test of MSW, pointed out a formula to describe the degradation regulation and a method to determine the parameters, built a settlement calculation model for MSW, gained the change regulations of the degradation velocity and the amount of degradation with time. Kong et al. [11] studied the long term deformation of MSW, got the linear relationship between settlement velocity and time in the double logarithmic coordinates. Zhan et al. [12] carried out the compression tests on 31 undisturbed waste samples from 5 drills in Qizi Mountain landfill, Suzhou, China, and gained the influences of filling age, composition, initial void ratio on the compression index of MSW. Zhang et al. [13] considered the actual filling process of a landfill, carried out the research on the calculation method of one dimensional compression, and established a calculation method for one dimensional compression of MSW.

On the basis of aforementioned researches, considering three kinds of mixture proportion, three kinds of initial density, four degradation times, four step loadings, and eight different compression times, using a large scale compression test instrument, a series of compression tests of degradation MSW were systematically carried out in the present paper.

\section{Compression test material and test process}

\subsection{Compression test material}

Referring to the main components of the MSW from Tianziling landfill, Hangzhou, China, the MSW samples were artificially made and the components of MSW 
were divided into three kinds which were easily degradable, difficulty degradable and incompressible solid waste material. Considering the effect of the size, the sizes of all the components were smaller than $1 / 6$ of the diameter of the compression chamber. To simulate the underdeveloped, developing, and developed stage of the development of social economy, three kinds of mixture proportion (MP) were selected (shown in table 1). The composition percentages of every component of the fresh MSW were list in tables 2-4. Stored the mixed samples in plastic bags, sealed, and let them degrade in a natural state for 30,60, 120 and 180 days, respectively, then the degraded waste samples were gained. Figure. 1 shows the degraded samples with different degradation time. Table 5 lists the moisture contents of degraded samples.

Table 1: $\quad$ Mixture proportions of fresh MSW (weight percentage).

\begin{tabular}{|c|c|c|c|}
\hline & $\begin{array}{c}\text { Easily } \\
\text { degradable } \\
\text { component / } \%\end{array}$ & $\begin{array}{c}\text { Difficult to degrade } \\
\text { component } / \%\end{array}$ & $\begin{array}{c}\text { Incompressible solid } \\
\text { waste material } / \%\end{array}$ \\
\hline $\begin{array}{c}\text { First kind mixture } \\
\text { proportion (MP1) }\end{array}$ & 50 & 15 & 35 \\
\hline $\begin{array}{c}\text { Second kind mixture } \\
\text { proportion (MP2) }\end{array}$ & 65 & 10 & 25 \\
\hline $\begin{array}{c}\text { Third kind mixture } \\
\text { proportion (MP3) }\end{array}$ & 80 & 5 & 15 \\
\hline
\end{tabular}

Table 2: $\quad$ Percentage composition of the easily degradable material.

\begin{tabular}{|c|c|c|c|c|}
\hline & Paper & Vegetable & Fruit skin & Grass, tree leaf, and wood \\
\hline MP1 & 2 & 36 & 9 & 3 \\
\hline MP2 & 2.6 & 46.8 & 11.7 & 3.9 \\
\hline MP3 & 3.2 & 57.6 & 14.4 & 4.8 \\
\hline
\end{tabular}

Table 3: Percentage composition of the difficulty degradable material.

\begin{tabular}{|c|c|c|c|c|}
\hline & Textile & Animal bone & Plastics & Rubber \\
\hline MP1 & 4.5 & 4.5 & 3 & 3 \\
\hline MP2 & 3 & 3 & 2 & 2 \\
\hline MP3 & 1.5 & 1.5 & 1 & 1 \\
\hline
\end{tabular}

Table 4: Percentage composition of the incompressible solid waste material.

\begin{tabular}{|c|c|c|c|c|}
\hline & Metal & Brick, stone, and soil & Ceramics & Glass \\
\hline MP1 & 1.75 & 29.75 & 1.75 & 1.75 \\
\hline MP2 & 1.25 & 21.25 & 1.25 & 1.25 \\
\hline MP3 & 0.75 & 12.75 & 0.75 & 0.75 \\
\hline
\end{tabular}


Table 5: $\quad$ Moisture content of the degraded waste.

\begin{tabular}{|c|c|c|c|c|}
\hline Degradation time $T / \mathrm{d}$ & 30 & 60 & 120 & 180 \\
\hline MP1 & 68.5 & 59.3 & 63.0 & 62.8 \\
\hline MP2 & 103.8 & 92.0 & 94.0 & 87.5 \\
\hline MP3 & 145.1 & 142.5 & 153.9 & 166.4 \\
\hline
\end{tabular}

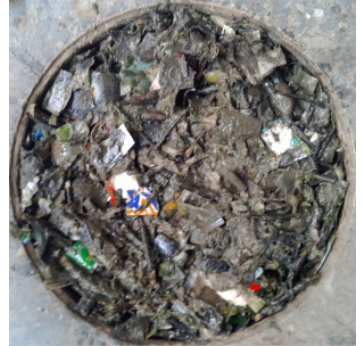

(a) 30 days

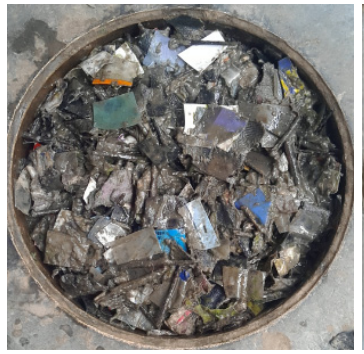

(c) 120 days

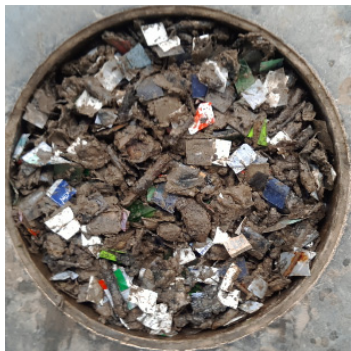

(b) 60 days

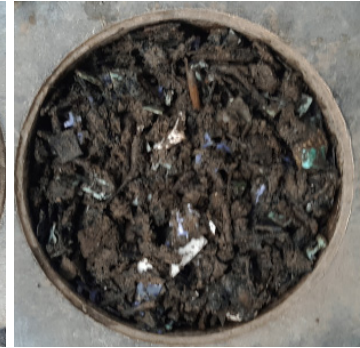

(d) 180 days

Figure 1: Degraded MSW samples with different degradation time.

\subsection{Compression test process}

The experiments were carried out on a large scale compression apparatus, the inner diameter of the compression chamber was $180 \mathrm{~mm}$, and the height of the compression chamber was $150 \mathrm{~mm}$.

The compression tests were carried out on three kind mixture proportions with three different initial densities $\left(950 \mathrm{~kg} / \mathrm{m}^{3}, 840 \mathrm{~kg} / \mathrm{m}^{3}\right.$, and $\left.760 \mathrm{~kg} / \mathrm{m}^{3}\right)$. The stepping loadings applied on the first kind mixture proportion sample were $25,50,100$, and $200 \mathrm{kPa}$, and the stepping loadings applied on the second kind and the third kind mixture proportion samples were $25,50,75$ and $100 \mathrm{kPa}$. The compression time for every stepping loading was $0.25,0.5,1,2,6,12$ and 24 hours. Besides, the degradation times were selected as 30,60, 120 and 180 days. 
The compression tests were carried out according to the Chinese specification of soil test [14]. After prepared the fresh MSW materials, weighted every component according to tables $1-4$, and then fully mixed. The specific gravity of each component was measured by the pycnometer method [15], and the weighted average specific gravity of the waste could be calculated according to the mixture proportion. The moisture content of the waste was measured by the drying method [15], and the initial void ratio of the waste was calculated by equation (1). The physical properties of the MSW samples were listed in table 6. Mixed the MSW sample well, and then stored it in a fresh keeping bag for degradation. The mixed samples degrade with time, and leachate will generate. Because the leachate has a strong corrosive, the fresh keeping bag can be corroded, therefore, it is necessary to package 4-5 layer plastic bag outside the fresh keeping bag, the plastic bag should be sealed and stored in a natural environment for the setting degradation time. With the development of degeneration, the oxygen in a landfill is gradually depleted, then the landfill is an anaerobic environment, so sealed the sample to simulate the real degradation environment of a landfill.

$$
e_{0}=\frac{d_{s} \rho_{w}(1+\omega)}{\rho}-1
$$

Here $e_{0}$ is the initial void ratio, $d_{\mathrm{s}}$ is the weighted average specific gravity, $\omega$ is the moisture content, and $\rho$ is the initial density of the sample.

Table 6: $\quad$ Physical properties of MSW samples.

\begin{tabular}{|c|c|c|c|}
\hline & Initial void ratio / $e_{0}$ & Moisture content $/ \%$ & Specific gravity \\
\hline MP1 & $2.1,2.5,2.9$ & 60 & 2.1 \\
\hline MP2 & $2.1,2.5,2.9$ & 134 & 2.05 \\
\hline MP3 & $2.1,2.5,2.9$ & 207 & 2.0 \\
\hline
\end{tabular}

Pulled the sample into the compression chamber, compacted the sample by the method of stratified compaction, then added MSW sample, and re-compaction, repeated above process till the chamber was full. During the process of sample loading, tried to keep the initial density of the sample as 950,840 , and $760 \mathrm{~kg} / \mathrm{m}^{3}$. Then, laid permeable stone and loading plate on the top of the sample, installed the dial indicator at the plate centre, adjusted the dial indicator and recorded the initial reading, thus the preparation of the experiment was finished.

The compression time for every stepping loading were selected as $0,0.25,0.5$, $1,2,6,12$, and 24 hours. For the convenience of description, taking the initial density was $950 \mathrm{~kg} / \mathrm{m}^{3}$ and the vertical pressure was $25 \mathrm{kPa}$ as an example to describe the test process. Exerted $25 \mathrm{kPa}$ vertical pressure, began timing, and recorded the readings of the dial indicator when the compression times were 0.25 , $0.5,1,2,6,12$, and 24 hours, respectively. Exerting the vertical pressure with 50, $100,200 \mathrm{kPa}$, respectively. For every stepping loading, recorded the readings of the dial indicator at the selected compression times. 


\section{Compression test results and analysis}

\subsection{Relationship between strain and vertical pressure}

For the convenience of description, taking the compression time is 24 hours as an example, relationship between the total strain of the MSW sample and logarithmic vertical pressure are shown in figures 2, 3 and 4. From these three figures, it can be found that the total strain $\left(\varepsilon_{t}\right)$ increases with vertical pressure, and the relationship can be fitted into a linear relation, and can be formulated as:

$$
\varepsilon_{t}=a+b \lg P
$$

Here $a$ and $b$ are parameters which have some connections with degradation time, mixture proportion, and initial density.

From figures 2, 3 and 4, it can be found that the curve has a tendency to move upward with degradation time. Under the action of same vertical pressure, the

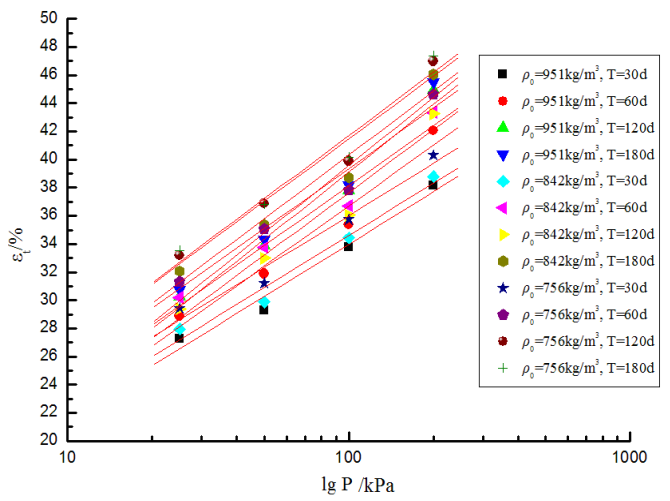

Figure 2: $\quad$ Total strain versus logarithmic vertical pressure for MP1.

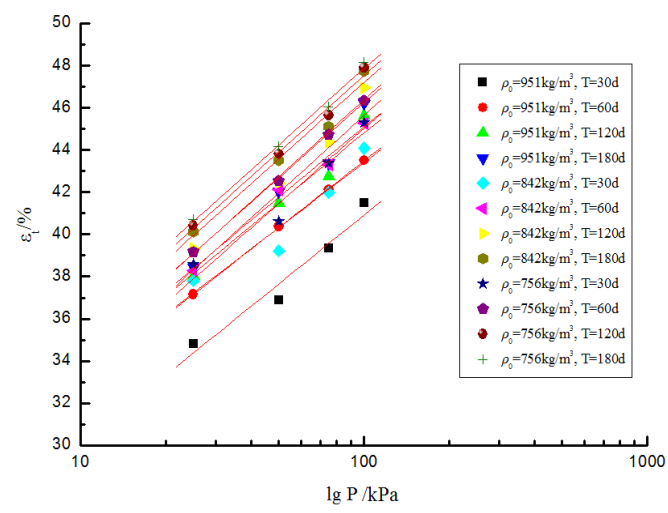

Figure 3: $\quad$ Total strain versus logarithmic vertical pressure for MP2. 


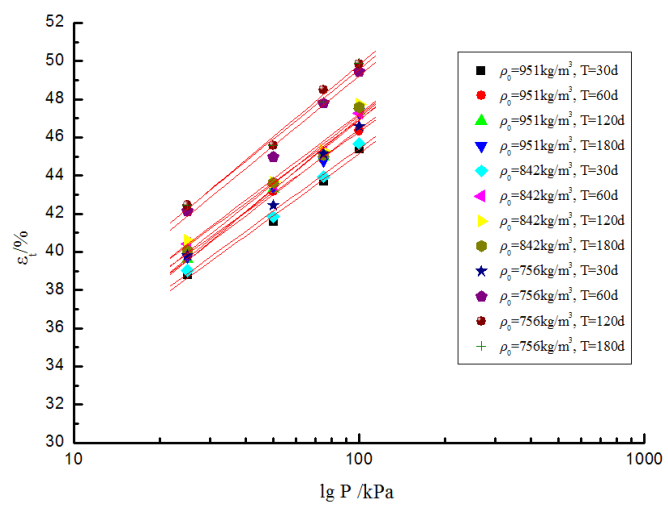

Figure 4: Total strain versus logarithmic vertical pressure for MP3.

longer the degradation time is, the larger is the total strain. This is because the easily degradable and easily compressible components in the MSW sample gradually reduce with the compression time, and converted into gas phase and liquid phase, thus the degradation strain increases and the compression strain decreases, and the total strain increases.

\subsection{Relationship between strain and compression time}

For the convenience of description, taking the first kind mixture proportion sample as an example, the relationship between compression strain and compression time is shown in figure 5. From this figure, it can be found that, no matter what the vertical pressure is and when the degradation time is, the compression strain increases with compression time, the increasing trend gradually slows down, and the curve finally tends to a horizontal line. From the test data, the compression strain with two hours' compression reaches $95 \%$ of the compression strain with 24 hours' compression. From figure 5, it can also be found the compression of MSW

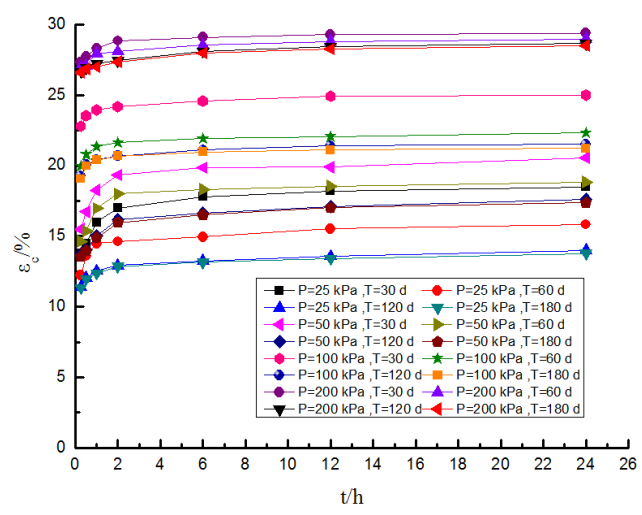

Figure 5: Compression strain versus compression time. 
gradually increases with vertical pressure, while the compression increment of MSW decreases with the increase of compression time. This is because the content of easily degradable component gradually reduces with compression time, thus the content of compressible component in the sample is reducing.

\subsection{Relationship between strain and density}

For the convenience of description, taking the second kind mixture proportion sample as an example, the relationship between the total strain $\left(\varepsilon_{t}\right)$ and density is shown in figure 6. For a same stepping load, the four data points are corresponding to degradation times are $30,60,120$ and 180 days respectively, in the direction from lower left to upper right. The data are recorded when the compression time reaches 24 hours. From figure 6 , it can be found that, the total strain of a degradation sample increases with density, and the relationship can be formulated by a straight line. The equation of the straight line is written as:

$$
\varepsilon_{t}=c+d \rho
$$

Here $c$ and $d$ are the parameters which have some connections with the mixture proportion, initial density, vertical pressure, and compression time.

Besides, from figure 6 , it can be found that, under the action of same pressure, the fitted line for a smaller initial density is in the upper position. This indicates that the total strain and density of the MSW sample increases with the decrease of initial density. In addition, with the same initial density, the fitted line moves to the right upper with the increase of vertical pressure. This indicates the total strain and the density of the MSW sample increases with vertical pressure.

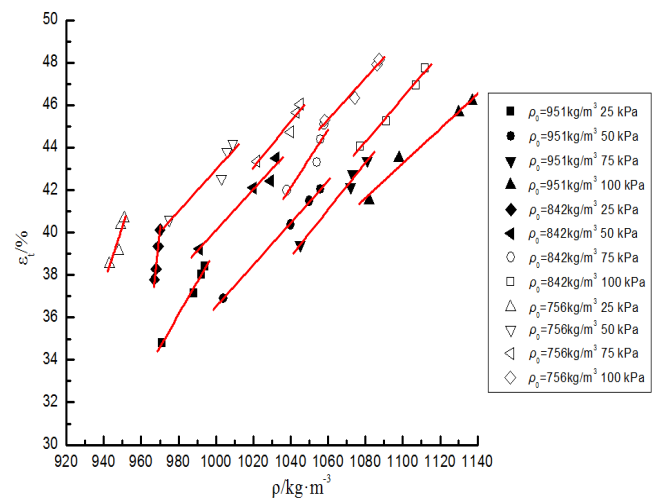

Figure 6: Total strain versus density.

\subsection{Relationship between density and degradation time}

The relationship between density and logarithmic degradation time of a MSW sample after 24 hours' compression are shown in figures 7, 8 and 9. From these 
figures, one can find the density of MSW samples increases with logarithmic degradation time, the relationship can be fitted into a straight line, the correlation coefficients are all bigger than 0.9 , and the straight line can be formulated as:

$$
\rho=e+f \lg T
$$

Here $e$ and $f$ are parameters that have some connections with degradation time, mixture proportion, initial density, and vertical pressure.

From figures 7, 8 and 9, it can be found that the curve has a tendency to move upward with vertical pressure. Under the same degradation time, the larger the vertical pressure is, the larger is the density after compression. This is because the MSW sample is compressed more and more tightly with the increase of vertical pressure, and the volume of the sample become smaller and smaller. Besides, at the same vertical pressure and same degradation time, the larger the initial density is, the larger is the density after compression. This is because the larger the initial density is, the smaller is the void ratio, the tighter is the sample.

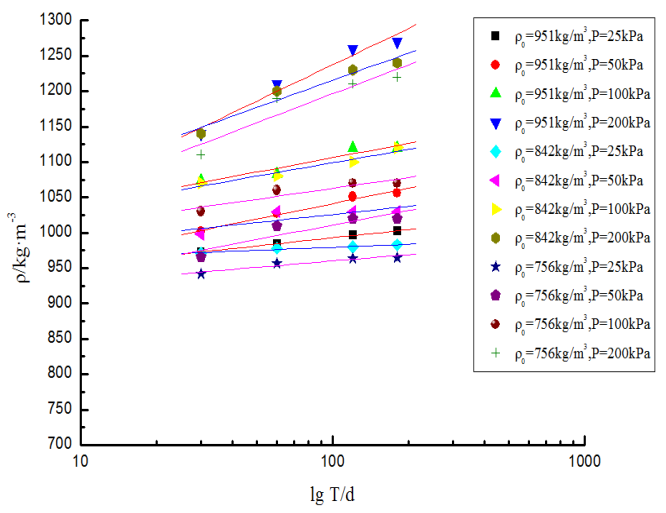

Figure 7: Density versus logarithmic degradation time for MP1.

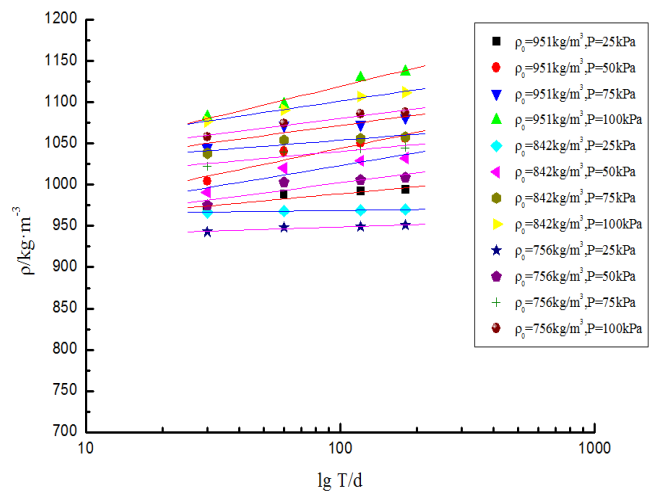

Figure 8: Density versus logarithmic degradation time for MP2. 


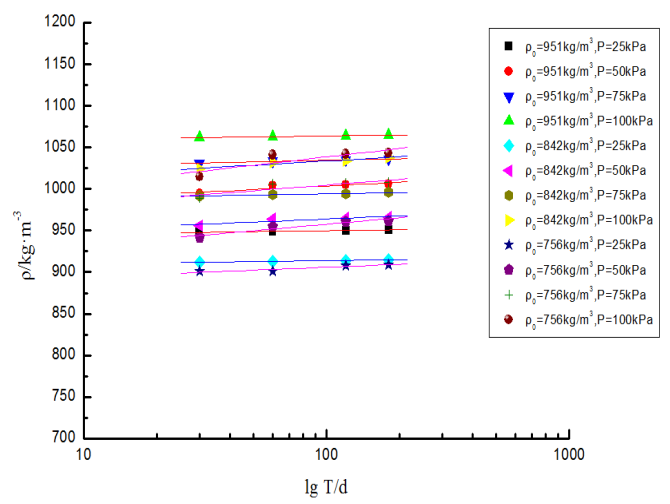

Figure 9: Density versus logarithmic degradation time for MP3.

\section{Conclusions}

Based on the compression tests on the degraded municipal solid waste, following conclusions can be drawn:

(1) Total compression strain of degraded MSW increases with vertical pressure, and the relationship can be expressed by a logarithmic model.

(2) The compression strain of degraded MSW increases with compression time, the increasing trend gradually slows down, and the curve finally tends to a horizontal line.

(3) The total strain of degraded MSW increases with density, and the relationship can be formulated by a straight line.

(4) The density of degraded MSW samples increases with degradation time, the tendency becomes more and more gentle, and the relationship can be described by a logarithm model.

\section{Acknowledgements}

This paper is funded by National Natural Science Foundation of China under contract No.51178432, 51478436, and by Natural Science Foundation of Zhejiang Province of China (No.LY14E080021), and by National Undergraduate Training Programs for Innovation of China (No.201410338014).

\section{References}

[1] Sowers, G.F., Foundation problem in sanitary landfills. Journal of Sanitary Engineering, 94(1), pp. 103-116, 1968

[2] Sowers, G.F., Settlement of waste disposal fills. Proceeding of $8^{\text {th }}$ International Conference on Soil Mechanic and Found Engineering, Moscow part 2, pp. 207-210, 1973. 
[3] Yue, B.C. \& Scanlon, B., Sanitary landfill settlement rates. Journal of Geotechnical and Geoenvironmental Engineering, 101(5), pp. 475-487, 1975.

[4] Gabr, M., \& Valero, S., Geotechnical properties of municipal solid waste. Geotechnical Testing Journal, 18(2), pp. 241-251, 1995.

[5] Hanson, J. L., Yesiller, N., Von Stockhausen, S. A.. \& Wong, W., Compaction characteristics of municipal solid waste. Journal of Geotechnical and Geo-environmental Engineering, 136(8), pp. 1095-1102, 2010.

[6] Hu, M.Y., Chen, Y.M. \& Wen, Z.T., Study on the compressibility and deformation of MSW in landfill. Chinese Journal of Geotechnical Engineering, 23(1), pp. 123-126, 2001.

[7] Ke, H., Chen, Y.M. \& Feng, S.J., Compression mechanism of municipal solid waste and settlement of a landfill, Proceedings of the Ninth Conference of Chinese Institution of Soil Mechanics and Geotechnical Engineering - China Civil Engineering Society. Beijing, 2003.

[8] Zhang, Z.Y. \& Chen Y.M., Settlement model of municipal solid waste landfill. Journal of Zhejiang University (Engineering Science), 38(9), pp. 1162-1165, 2004.

[9] Zhang, Z.Y., Study on Compressibility and Settlement of Landfill for Municipal Solid Waste. Ph. D Thesis. Zhejiang University, China. 2005.

[10] Chen, J.D., Shi, J.Y. \& Fang Y.F., Degradation law of municipal solid waste and settlement calculation of landfills. Journal of Hohai University (Natural Sciences), 34(6), pp. 680-682, 2006.

[11] Kong, X.J., Sun, X.L. \& Zou, D.G., Creep-degradation properties of municipal solid waste in laboratory tests. Rock and Soil Mechanics, 29(2), pp. 337-341, 2008.

[12] Zhan, L.T., Wei H.Y. \& Chen Y.M., Mechanical compressibility of in-site municipal solid wastes and its relationship to fill ages. Journal of Zhejiang University (Engineering Science), 42(2), pp. 353-358, 2008.

[13] Zhang, Z.Y., Yang, Y.F. \& Wu, C.F., Study on the calculation method of one-dimension stress compression for municipal solid waste. Journal of Zhejiang Sci-Tech University, 26(1), pp. 132-136, 2009.

[14] Industry standard of P.R. China, Specification for Soil Test (SL237-1999). The Ministry of Water Resources of the People's Republic of China. 1999.

[15] Yan, S., Study on the engineering properties of municipal solid waste. Master Thesis. Institute of Rock and Soil Mechanics, Chinese Academy of Science, China. 2004. 